\title{
Association between PPARy2 Pro12Ala polymorphism and myocardial infarction and obesity in Han Chinese in Hohhot, China
}

\author{
L.P. Wang ${ }^{*}$, L.R. Zhao ${ }^{2 *}$, H.W. Cui ${ }^{3}$, M.R. Yan $^{3}$, L. Yang ${ }^{3}$ and X.L. Su ${ }^{3}$ \\ ${ }^{1}$ Department of Cardiology of Affiliated Hospital, \\ Inner Mongolia Medical College, Hohhot, China \\ 2Internal Medicine, Inner Mongolia Third Hospital, Hohhot, China \\ ${ }^{3}$ Clinical Research Center of Affiliated Hospital, \\ Inner Mongolia Medical College, Hohhot, China \\ *These authors contributed equally to this study. \\ Corresponding author: X.L. Su \\ E-mail: xlsu@hotmail.com
}

Genet. Mol. Res. 11 (3): 2929-2938 (2012)

Received September 26, 2011

Accepted January 30, 2012

Published May 18, 2012

DOI http://dx.doi.org/10.4238/2012.May.18.13

\begin{abstract}
Activation of the peroxisome proliferator-activated receptor $\gamma(\operatorname{PPAR} \gamma)$ improves insulin sensitivity and inhibits atherosclerosis. Whether PPAR $\gamma 2$ Pro12Ala polymorphism affects myocardial infarction is not clearly understood. We investigated a possible association of PPAR $\gamma 2$ Pro12Ala polymorphism with obesity and myocardial infarction in Han Chinese in Hohhot, Inner Mongolia, China. We included 121 subjects with myocardial infarction and 137 healthy controls in our study. Triglycerides, total cholesterol, lowdensity lipoprotein cholesterol, and high-density lipoprotein cholesterol were measured. The following information was recorded for each subject: age, gender, body height, body weight, systolic blood pressure, and diastolic blood pressure; the body mass index was calculated. PCRRFLP was used to examine the Pro12Ala polymorphism. There were significant differences in clinical characteristics between myocardial infarction patients and healthy controls, except for diastolic blood
\end{abstract}


pressure and triglycerides. The PP, PA/AA genotype frequencies were 88.4 and $11.6 \%$ in myocardial infarction patients and 95.6 and $4.4 \%$ in controls, respectively $(\mathrm{P}=0.031)$. Individuals with the $\mathrm{A}$ allele had a significantly higher risk of myocardial infarction. The A allele was not an independent risk factor for obesity. We conclude that PPAR $\gamma 2$ Pro12Ala polymorphisms are associated with increased risk for myocardial infarction in Han Chinese in Hohhot.

Key words: Peroxisome proliferator-activated receptor $\gamma$; PCR-RFLP; Cardiovascular disease; Body mass index

\section{INTRODUCTION}

Myocardial infarction (MI) is the leading cause of death for both men and women worldwide (McDermott, 2007). Insulin resistance, atherosclerosis and dyslipidemia are important factors contributing to MI. The incidence of MI is increasing each year; however, the etiology of the disease is not clearly explained. The molecular mechanism of MI can be elucidated with a thorough study of the genetics of the disease.

Peroxisome proliferator-activated receptors (PPARs) were found by Issemann and Green (1990). PPARs are members of the type II nuclear hormone receptor superfamily, which consists of three subtypes (PPAR $\alpha, \beta / \delta$, and $\gamma$ ). PPAR $\gamma$ highly expressed in adipose tissue and colon and moderately expressed in liver, heart and kidney. The PPAR $\gamma$ is a transcription factor that belongs to the same family as the steroid and thyroid hormone receptors. The human PPAR $\gamma$ gene is located on chromosome $3 \mathrm{p} 25$ and produces 3 different molecules (PPAR $\gamma 1$, PPAR $\gamma 2$, and PPAR $\gamma 3$ ) by alternative mRNA splicing. There are additional 28 amino acids on the N-terminal of PPAR $\gamma 2$, which are coded by exon B. PPAR $\gamma 2$ is mainly found in adipose tissue, where it plays roles in regulating target genes, metabolism of fat and sugar, insulin resistance, obesity, cell differentiation and proliferation, inflammation, and atherosclerosis (Hsueh and Bruemmer, 2004). Activation of PPAR $\gamma 2$ increases insulin sensitivity (Miyazaki et al., 2001), anti-atherosclerosis (Hu et al., 2010), anti-inflammation (Wang et al., 2005), and anti-oxidation (Ren et al., 2009), improves high blood pressure and dyslipidemia, and reduces the risk of cardiovascular disease (Tavares et al., 2005). A cytosine to guanine substitution in exon B of the PPAR $\gamma 2$ gene results in a change of proline (Pro) to alanine (Ala). The Ala variant has lower affinity for the response element and a lower capacity for activating target genes by about 50\% (Tamori et al., 2002). It has been shown that insulin sensitivity, inflammation, dyslipidemia have an important role in MI (Holvoet, 2008). Therefore, based on the current studies, we hypothesized that PPAR $\gamma 2$ Pro12Ala polymorphism may be associated with MI. In this study, we investigated the correlation between PPAR $\gamma 2$ Pro12Ala polymorphism and MI in Han Chinese in Inner Mongolia to provide data to help elucidate the mechanism of MI.

\section{MATERIAL AND METHODS}

\section{Subjects}

All subjects gave informed consent. One hundred and twenty one MI patients (72 
males and 49 females, ranging from 51-80 years) with an average age of $65.28 \pm 7.89$ years old were enrolled. All patients were diagnosed according to the criteria of the World Health Organization, which include chest pain plus either electrocardiogram (ECG, elevated or depressed ST, or abnormal Q wave) or elevated levels of cardiac enzymes (Rose and Blackburn, 1982). Individuals with complicated diabetes and other metabolic diseases, severe liver and kidney dysfunction or cancers were excluded from the study. One hundred and thirty seven healthy controls (79 males and 58 females, ranging from 45-85 years) with an average age of $63.15 \pm$ 10.32 years old were selected by routine physical examination. The controls excluded those with cardiovascular and cerebrovascular diseases, diabetes, and liver and kidney dysfunction by medical history, physical examination, laboratory tests, ECG, X-ray, and ultrasound examination. All the subjects did not take lipid-lowering drugs for 2 months. Our study was approved by the Inner Mongolia Medical College Affiliated Hospital Ethics Committee.

Body mass index (BMI) was calculated by weight $(\mathrm{kg})$ divided by square height $\left(\mathrm{m}^{2}\right)$. According to the situation in China (Liu et al., 2001), BMI $<26$ was considered as non-obesity, BMI $\geq 26$ as obesity. Blood pressure (systolic blood pressure (SBP) and diastolic blood pressure (DBP)) was measured three times for each subjects and the average was used. Blood samples were drawn after an overnight fast. Total plasma cholesterol (TC), triglycerides (TG), high-density lipoprotein cholesterol (HDL-C), and low-density lipoprotein cholesterol (LDLC) were measured according to standardized methods (Beckman Coulter Unicel DxC 800 Synchron Clinical Systems; Beckman Coulter Company, Fullerton, CA, USA). Hyperlipemia was diagnosed as TG $>150 \mathrm{mg} / \mathrm{dL}(1.7 \mathrm{mM})$ and/or TC $>220 \mathrm{mg} / \mathrm{dL}(5.72 \mathrm{mM})$ and/or LDL$\mathrm{C}>140 \mathrm{mg} / \mathrm{dL}(3.64 \mathrm{mM})$.

\section{DNA isolation and TaqMan PCR}

Genomic DNA was extracted by a kit (TIANamp Blood DNA kit, TIANGEN, Beijing, China). The PPAR $\gamma 2$ Pro12Ala polymorphism (rs1801282) was analyzed using polymerase chain reaction-restriction fragment length polymorphism (PCR-RFLP). PCR was performed in a volume of $25 \mu \mathrm{L}$ including $10.1 \mu \mathrm{L}$ ddH $_{2} \mathrm{O}, 12.5 \mu \mathrm{L} 2 \mathrm{X}$ Taq Master Mix (Promega), $0.2 \mu \mathrm{L}$ primer [sense 5'-CCAATTCAAGCCCAGTCCTTTC-3' and antisense 5'-CAGTGAAGGAATCGCTT TCCG-3' (Issemann and Green, 1990)] and $2 \mu \mathrm{L}$ template DNA. The reaction conditions were as follows: initial denaturation at $95^{\circ} \mathrm{C}$ for $5 \mathrm{~min}$, followed by 35 cycles of denaturation at $94^{\circ} \mathrm{C}$ for $40 \mathrm{~s}$, annealing at $55^{\circ} \mathrm{C}$ for $50 \mathrm{~s}$, and extension at $72^{\circ} \mathrm{C}$ for $1 \mathrm{~min}$; with a final extension at $72^{\circ} \mathrm{C}$ for 7 min. PCR products were digested with Bst U-I (New England BioLabs, Beijing, China) in a $60^{\circ} \mathrm{C}$ water bath for $2 \mathrm{~h}$. Digestion products $(7 \mu \mathrm{L})$ were electrophoresed using a $4 \%$ agarose gel at $120 \mathrm{~V}$ for $1 \mathrm{~h}$ and analyzed with a Gel-Pro imaging instrument.

\section{Sequencing}

To confirm that the detection of this $\mathrm{C} \rightarrow \mathrm{G}$ nucleotide substitution by PCR-RFLP analysis was reproducible, we also performed PCR-based direct sequencing analysis. The genotype of each study subject was determined blindly without knowledge of clinical status. PP and AA genotypes were selected and re-amplified, and the DNA sequences were verified by direct sequencing (United States ABI Prism 3700 DNA analyzer 377; Applied Biosystems, Foster City, CA, USA). 


\section{Statistical analysis}

All clinical and biochemical data were expressed as mean \pm standard deviation. The comparison of average clinical data between groups was performed by the independent sample $t$-test. The chi-square test was used to compare genotype and allele frequencies between groups and to determine whether individual variants were in accord with Hardy-Weinberg equilibrium. Dualistic logistic regression was used to investigate the risk factor of myocardial infarction and obesity. The factors with $\mathrm{P}<0.05$ in univariate regression were further analyzed in multivariate logistic regression. Statistical analysis was performed by the SPSS 13.0 software. Statistical significance was established at $\mathrm{P}<0.05$.

\section{RESULTS}

The clinical characteristics of MI patients and healthy controls are shown in Table 1. The age and gender of two groups were well matched. There was a significant difference in clinical characteristics between MI patients and healthy controls except DBP and TG.

\begin{tabular}{|c|c|c|c|}
\hline & Control & MI & $\mathrm{P}$ \\
\hline Males / females & $137(79 / 58)$ & $121(72 / 49)$ & \\
\hline Age (years) & $50.08 \pm 15.01$ & $53.47 \pm 16.21$ & 0.232 \\
\hline SBP (mmHg) & $120.61 \pm 12.33$ & $134.14 \pm 19.63$ & $0.000 *$ \\
\hline $\mathrm{DBP}(\mathrm{mmHg})$ & $73.91 \pm 10.66$ & $73.80 \pm 11.68$ & 0.937 \\
\hline BW (kg) & $66.08 \pm 11.13$ & $72.65 \pm 10.00$ & $0.000 *$ \\
\hline BMI $\left(\mathrm{kg} / \mathrm{m}^{2}\right)$ & $23.44 \pm 2.88$ & $25.81 \pm 2.82$ & $0.000 *$ \\
\hline $\mathrm{TG}(\mathrm{mM})$ & $1.60 \pm 1.09$ & $1.74 \pm 0.11$ & 0.143 \\
\hline $\mathrm{TC}(\mathrm{mM})$ & $4.71 \pm 0.85$ & $5.93 \pm 0.55$ & $0.000^{*}$ \\
\hline LDL-C (mM) & $2.74 \pm 0.63$ & $4.20 \pm 0.35$ & $0.000 *$ \\
\hline HDL-C (mM) & $1.39 \pm 0.43$ & $0.16 \pm 0.17$ & $0.000 *$ \\
\hline
\end{tabular}

The independent sample $t$-test was used to compare clinical characteristics between myocardial infarction patients and healthy controls. Data are reported as means \pm standard deviations. *Indicates significant difference between groups. $\mathrm{MI}=$ myocardial infarction; $\mathrm{SBP}=$ systolic blood pressure; $\mathrm{DBP}=$ diastolic blood pressure; $\mathrm{BW}=$ body weight; $\mathrm{BMI}=$ body mass index; $\mathrm{TG}=$ triglycerides; $\mathrm{TC}=$ total cholesterol; LDL-C $=$ low-density lipoprotein cholesterol; HDL-C = high-density lipoprotein cholesterol.

The DNA fragment of the PPAR- $\gamma 2$ gene was 244 bp after PCR amplification. The expected sizes of the products after digestion with Bst U-I were the following: homozygous wild-type (PP) without a restriction site and an electrophoresis band of $244 \mathrm{bp}$; mutant homozygote (AA) with a restriction site in each DNA chain, resulting in electrophoresis bands of 223 and $21 \mathrm{bp}$; and heterozygote (PA) with restriction sites in one of the DNA chains, resulting in 3 electrophoresis bands at 244, 223, and $21 \mathrm{bp}$.

In the subjects we studied, the incidence of PPAR- $\gamma 2$ gene P/P, P/A and A/A genotypes was 92.2, 6.2 and 1.6\%, respectively; the incidence of PPAR- $\gamma 2$ gene $P$ and A alleles was 95.3 and $4.7 \%$, respectively. We observed that the PPAR- $\gamma 2$ Pro12Ala polymorphism genotype distribution was in accordance with Hardy-Weinberg expectations in each group (MI, $\chi^{2}=1.423$, $\mathrm{P}=0.491$; healthy controls, $\chi^{2}=0.079, \mathrm{P}=0.961$; obesity, $\chi^{2}=0.898, \mathrm{P}=0.638$; non-obesity, $\chi^{2}=3.517, \mathrm{P}=0.172$ ). It showed that the study groups were representative.

The PPAR- $\gamma 2$ gene P/P, P/A and A/A genotype distributions were 88.4, 11.6 and $0.0 \%$ 
in MI patients and 95.6, 1.5 and 2.9\% in healthy controls, respectively. The P allele frequency in patients and healthy controls was 94.2 and $96.4 \%$, and the A allele frequency was 5.8 and $3.6 \%$, respectively. There was a significant difference in frequencies of PPAR- $\gamma 2$ genotypes $\mathrm{PP}$ and PA/AA between MI patients and healthy controls $(\mathrm{P}=0.031$, Table 2$)$. The frequency of PPAR- $\gamma 2$ gene P/P, P/A and A/A genotype was $89.8,7.9$, and $2.3 \%$ in obesity and $93.5,5.3$ and $1.2 \%$ in non-obesity, respectively. The $\mathrm{P}$ allele frequency in obesity and non-obesity was 93.75 and $96.15 \%$ and the A allele frequency was 6.25 and 3.85\%, respectively. There was no significant difference in distribution of PPAR- $\gamma 2$ genotype frequency between obesity and non-obesity $(\mathrm{P}>0.05$, Table 2$)$.

\begin{tabular}{|c|c|c|c|c|}
\hline \multirow[t]{2}{*}{ Group } & \multicolumn{2}{|c|}{ Obesity } & \multicolumn{2}{|c|}{ Myocardial infarction } \\
\hline & Obese $(\mathrm{N}=88)$ & Non-obese $(\mathrm{N}=170)$ & MI $(\mathrm{N}=121)$ & Control $(\mathrm{N}=137)$ \\
\hline \multicolumn{5}{|c|}{ Genotype } \\
\hline PP & $79(89.8 \%)$ & $159(93.5 \%)$ & $107(88.4 \%)$ & $131(95.6 \%)$ \\
\hline PA & $7(7.9 \%)$ & $9(5.3 \%)$ & $14(11.6 \%)$ & $2(1.5 \%)$ \\
\hline AA & $2(2.3 \%)$ & $2(1.2 \%)$ & $0(0.0 \%)$ & $4(2.9 \%)$ \\
\hline $\mathrm{P}$ & 0.285 & 0.031 & & \\
\hline \multicolumn{5}{|l|}{ Allele } \\
\hline $\mathrm{P}$ & $165(93.75 \%)$ & $327(96.15 \%)$ & $228(94.2 \%)$ & $264(96.4 \%)$ \\
\hline A & $11(6.25 \%)$ & $13(3.85 \%)$ & $14(5.8 \%)$ & $10(3.6 \%)$ \\
\hline$P$ & 0.215 & 0.250 & & \\
\hline
\end{tabular}

Data are reported as numbers with frequencies in parentheses. Because there were too fewer individuals with AA genotype, AA genotype was combined with PA genotype in the chi-square test. MI = myocardial infarction.

We investigated the difference in clinical characteristics between individuals with PP and PA/AA genotypes in all subjects, MI patients, healthy controls, obesity and non-obesity, respectively. We found that the level of TC was significantly higher in PP subjects than in PA/ AA subjects $(\mathrm{P}=0.006$, Table 3$)$. A high level of TC was also found in MI patients and nonobese subjects with PP genotype $(P=0.007$ and 0.039 , respectively, Table 4,5$)$. There was a much lower level of HDL-C in non-obesity with PA/AA genotype than in non-obesity with PP genotype ( $\mathrm{P}=0.022$, Table 5). There was no significant difference in clinical characteristics between healthy control and obesity with PP and PA/AA genotype.

\begin{tabular}{lccc}
\multicolumn{5}{l}{ Table 3. Comparison of clinical characteristics between PP and PA/AA genotype carriers in all subjects. } \\
\hline & PP & PA/AA & P \\
\hline Number $(258)$ & 238 & 20 & 0.753 \\
Age (years) & $64.11 \pm 9.28$ & $63.25 \pm 14.55$ & 0.188 \\
BW (kg) & $68.90 \pm 11.27$ & $72.30 \pm 8.32$ & 0.230 \\
BMI (kg/m) & $24.49 \pm 3.12$ & $25.35 \pm 2.61$ & 0.323 \\
SBP $(\mathrm{mmHg})$ & $126.29 \pm 17.09$ & $130.25 \pm 18.44$ & 0.741 \\
DBP $(\mathrm{mmHg})$ & $73.45 \pm 10.40$ & $74.25 \pm 10.31$ & 0.558 \\
TG $(\mathrm{mM})$ & $1.69 \pm 0.87$ & $1.57 \pm 0.46$ & $0.006^{*}$ \\
TC $(\mathrm{mM})$ & $5.24 \pm 0.93$ & $5.84 \pm 0.99$ & 0.063 \\
LDL-C $(\mathrm{mM})$ & $3.39 \pm 0.90$ & $3.78 \pm 0.71$ & 0.637 \\
HDL-C (mM) & $1.34 \pm 7.82$ & $0.51 \pm 0.61$ & \\
\hline
\end{tabular}

The independent sample $t$-test was used to compare clinical characteristics between PP and PA/AA genotype carriers. Data are reported as means \pm standard deviations. *Indicates significant difference between groups. $\mathrm{BW}=$ body weight; $\mathrm{BMI}=$ body mass index; $\mathrm{SBP}=$ systolic blood pressure; $\mathrm{DBP}=$ diastolic blood pressure; $\mathrm{TG}=$ triglycerides; $\mathrm{TC}=$ total cholesterol; LDL-C $=$ low-density lipoprotein cholesterol; HDL-C = high-density lipoprotein cholesterol. 


\begin{tabular}{|c|c|c|c|}
\hline & PP & $\mathrm{PA} / \mathrm{AA}$ & $\mathrm{P}$ \\
\hline Number (121) & 107 & 14 & \\
\hline Age (years) & $63.36 \pm 14.75$ & $64.67 \pm 21.46$ & 0.551 \\
\hline $\mathrm{BW}(\mathrm{kg})$ & $72.73 \pm 10.28$ & $72.07 \pm 7.87$ & 0.818 \\
\hline BMI $\left(\mathrm{kg} / \mathrm{m}^{2}\right)$ & $25.83 \pm 2.90$ & $25.67 \pm 2.18$ & 0.844 \\
\hline SBP (mmHg) & $134.34 \pm 19.56$ & $132.64 \pm 20.86$ & 0.763 \\
\hline DBP (mmHg) & $73.71 \pm 11.81$ & $74.50 \pm 11.06$ & 0.813 \\
\hline $\mathrm{TG}(\mathrm{mM})$ & $1.73 \pm 0.11$ & $1.75 \pm 0.14$ & 0.614 \\
\hline $\mathrm{TC}(\mathrm{mM})$ & $5.40 \pm 0.48$ & $6.18 \pm 0.92$ & $0.007^{*}$ \\
\hline LDL-C (mM) & $4.21 \pm 0.34$ & $4.09 \pm 0.43$ & 0.228 \\
\hline HDL-C (mM) & $1.28 \pm 11.68$ & $0.14 \pm 0.75$ & 0.718 \\
\hline
\end{tabular}

The independent sample $t$-test was used to compare clinical characteristics between PP and PA/AA genotype carriers. Data are reported as means \pm standard deviations. *Indicates significant difference between groups. $\mathrm{BW}=$ body weight; $\mathrm{BMI}=$ body mass index; $\mathrm{SBP}=$ systolic blood pressure; $\mathrm{DBP}=$ diastolic blood pressure; $\mathrm{TG}=$ triglycerides; $\mathrm{TC}=$ total cholesterol; LDL-C $=$ low-density lipoprotein cholesterol; HDL-C = high-density lipoprotein cholesterol.

Table 5. Comparison of clinical characteristics between PP and PA/AA genotype carriers in non-obesity group.

\begin{tabular}{lccc}
\hline & PP & PA/AA & P \\
\hline Number (169) & 158 & 11 & 0.260 \\
Age (years) & $55.87 \pm 15.54$ & $61.27 \pm 11.82$ & 0.335 \\
SBP (mmHg) & $125.00 \pm 16.91$ & $130.18 \pm 20.91$ & 0.833 \\
DBP (mmHg) & $72.54 \pm 11.17$ & $73.27 \pm 8.95$ & 0.737 \\
TG (mM) & $1.61 \pm 0.84$ & $1.52 \pm 0.42$ & $0.039^{*}$ \\
TC (mM) & $5.40 \pm 0.48$ & $6.18 \pm 0.92$ & 0.216 \\
LDL-C (mM) & $3.24 \pm 0.84$ & $3.57 \pm 0.80$ & $0.022^{*}$ \\
HDL-C (mM) & $0.97 \pm 0.69$ & $0.47 \pm 0.62$ & \\
\hline
\end{tabular}

The independent sample $t$-test was used to compare clinical characteristics between PP and PA/AA genotype carriers. Data are reported as means \pm standard deviations. *Indicates significant difference between groups. SBP = systolic blood pressure; $\mathrm{DBP}=$ diastolic blood pressure; $\mathrm{TG}=$ triglycerides; $\mathrm{TC}=$ total cholesterol; LDL-C = low-density lipoprotein cholesterol; HDL-C = high-density lipoprotein cholesterol.

Univariate logistic regression showed that a high level of SBP, MBI, TG, TC, and LDL-C and low level of HDL-C and PPAR- $\gamma 2$ A allele $(\mathrm{OR}=2.857,95 \% \mathrm{CI}=1.062-7.687$, $\mathrm{P}=0.038$ ) was a risk factor of MI. However, in multivariate logistic regression, only MBI, $\mathrm{TG}, \mathrm{TC}$, and PPAR- $\gamma 2 \mathrm{~A}$ allele was a risk factor of $\mathrm{MI}(\mathrm{OR}=2.684,95 \% \mathrm{CI}=1.037-6.951, \mathrm{P}$ $=0.042$, Table 6). Univariate logistic regression showed that a high level of SBP, DBP, TG, $\mathrm{TC}$, and LDL-C and low level of HDL-C and PPAR- $\gamma 2 \mathrm{~A}$ allele $(\mathrm{OR}=3.437,95 \% \mathrm{CI}=1.116-$ $10.589, \mathrm{P}=0.031)$ was a risk factor of obesity. However, in multivariate logistic regression, DBP and HDL-C but not the PPAR- $\gamma 2$ A allele $(\mathrm{OR}=2.651,95 \% \mathrm{CI}=0.825-8.517, \mathrm{P}=0.102$, Table 7) was a risk factor of obesity.

Table 6. Multivariate logistic regression analysis of risk factors of myocardial infarction.
\begin{tabular}{lccr}
\hline Risk factor & OR & $95 \% \mathrm{CI}$ & $\mathrm{P}$ \\
\hline BMI & 1.967 & $1.461-2.648$ & $<0.000$ \\
PA/AA genotype & 2.684 & $1.037-6.951$ & 0.042 \\
TG & 2.470 & $1.471-4.147$ & 0.001 \\
TC & 10.414 & $6.163-17.595$ & 0.000 \\
\hline BMI = body mass index; TG = triglycerides; TC = total cholesterol; OR = odds ratio; 95\%CI $=95 \%$ confidence intervals.
\end{tabular}




Table 7. Multivariate logistic regression analysis of risk factors of obesity.
\begin{tabular}{lccr}
\hline Risk factor & OR & $95 \%$ CI & $<$ \\
\hline DBP & 4.895 & $1.032-23.214$ & $<0.046$ \\
PA/AA genotype & 2.651 & $0.825-8.517$ & 0.102 \\
HDL-C & 3.532 & $2.070-6.028$ & 0.000 \\
\hline
\end{tabular}

$\overline{\mathrm{DBP}}=$ diastolic blood pressure; HDL-C $=$ high-density lipoprotein cholesterol; OR $=$ odds ratio; $95 \% \mathrm{CI}=95 \%$ confidence intervals.

\section{DISCUSSION}

The PPAR- $\gamma 2$ Pro12Ala polymorphism was first discovered by Yen et al. (1997). The incidence of PPAR- $\gamma 2$ Pro12Ala polymorphism varied in different ethnic groups. The frequency of A allele was 10, 3 and 2\% in Mexican- and African-Americans and Nauruns, respectively (Kagawa et al., 2002; Wei et al., 2006; Black et al., 2008). Our study found that the incidence of the A allele was $3.6 \%$ in healthy controls, which was lower than that in Caucasians (11$13 \%$ ) (Schaffler et al., 2001; Kolehmainen et al., 2003), but was similar to that in a population of East Asia such as Koreans (3.5\%) (Kim et al., 2004), Chinese (4.2\%) (Pan et al., 2009) and Japanese (4.1\%) (Mori et al., 2001).

Association between PPAR- $\gamma 2$ and diseases has been intensively studied. Several polymorphisms have been found, including Pro12Ala, C161T, Pro115Gln, Pro467Leu, Val290Met and C-689T. The most common polymorphism is Pro12Ala. Regarding the association of the PPAR- $\gamma 2$ Pro12Ala polymorphism and type 2 diabetes and MI, controversial data have been published. Deeb et al. (1998) reported that individuals with allele A showed reduced risk of developing type 2 diabetes by $75 \%$. The analysis of 6 studies revealed that individuals with allele A had reduced the risk of developing type 2 diabetes by $21 \%$ (Altshuler et al., 2000). On the contrary, no association between PPAR- $\gamma 2$ Pro12Ala polymorphism and type 2 diabetes was also found (Stefanski et al., 2006). Ridker et al. (2003) found that PPAR- $\gamma 2$ Pro12Ala polymorphism was associated with MI, while Zafarmand et al. (2008) reported that PPAR- $\gamma 2$ Pro12Ala polymorphism was not a risk factor of MI. The controversial results may due to differences in ethnic groups, regions, number of samples, and environment.

Our study found that PPAR- $\gamma 2$ Pro12Ala polymorphism was an independent risk factor of MI. Foam cell differentiation, inflammation and cell proliferation play key roles in the formation of atherosclerosis plague. Studies have demonstrated that PPAR- $\gamma$ has a role in antiinflammation (Bouhlel et al., 2007). It was reported that PPAR- $\gamma 2$ inhibits the formation of plague. PPAR- $\gamma 2$ induced release of fat from foam cell by improving transcription of liver X receptor and activating ATP binding cassette transporter A1 (Akiyama et al., 2002). PPAR- $\gamma 2$ inhibits the proliferation of vascular smooth muscle cells by decreasing expression of MMP-9 and angiotensin II type I receptor (Ji et al., 2009; Moran et al., 2009). Multiple functions of PPAR- $\gamma 2$ have shown protection from developing MI. The low activity of the protein may result in metabolic disorders, inflammation and atherosclerosis. Therefore, PPAR- $\gamma 2$ Pro12Ala polymorphism may play an important role in MI.

PPAR- $\gamma 2$ has been found in white adipose tissue, and is involved in the differentiation of adipocytes and metabolism of fat (Iwai et al., 2011). Therefore, we investigated the association between PPAR- $\gamma 2$ Pro12Ala polymorphism and obesity. Many studies have indicated that PPAR- $\gamma 2$ Pro12Ala polymorphism is correlated with obesity, insulin resistance and 
hyperlipidemia. Beamer et al. (1998) found that PPAR- $\gamma 2$ Pro12Ala polymorphism was associated with high level of body weight, BMI and waistline in 169 obese Caucasians (average BMI $=36.5 \mathrm{~kg} / \mathrm{m}^{2}$ ), Meirhaeghe et al. (2000) reported that PPAR- $\gamma 2$ Pro12Ala polymorphism correlated with obesity and blood fat. On the contrary, PPAR- $\gamma 2$ Pro12Ala polymorphism was found to be associated with low body weight and high insulin sensitivity in 333 Finns (Deeb et al., 1998). There was no relation found between PPAR- $\gamma 2$ Pro12Ala polymorphism and obesity and distribution of fat in 215 Japanese (Mori et al., 1998).

Our result did not reveal an association between PPAR- $\gamma 2$ Pro12Ala polymorphism and obesity. The level of BMI and body weight was higher in individuals with PA/AA genotype than in individuals with PP genotype, but without significant difference. Kim et al. (2004) found that individuals with A allele had higher body weight, BMI and waist-to-hip ratio (P $<0.05$ ). Meta-analysis of 30 independent studies revealed that individuals with A allele had higher BMI (Masud and Ye, 2003). The incidence of A allele was associated with obesity in middle-aged males from Spain (Beamer et al., 1998), in Java (Danawati et al., 2005), and among Caucasians (Beamer et al., 1998). We investigated the controversial result more carefully, and found that the differences in results may be due to small sample of our study, different criterion (BMI) to define obesity, different distribution of A allele and BMI between different ethnic groups. The incidence of A allele was correlated with BMI in a population with BMI $>27$, while not in a population with BMI $<27$ (Masud and Ye, 2003). Additionally, PPAR- $\gamma 2$ Pro12Ala polymorphism was not associated with obesity in France (Ghoussaini et al., 2005) and Japan (Yamamoto et al., 2002). In out study, Logistic regression showed that PPAR- $\gamma 2$ Pro12Ala polymorphism was not a risk factor of obesity in our local region.

We found that PPAR- $\gamma 2$ Pro12Ala polymorphism was a risk factor of MI. In our study, we excluded MI patients with complicated diabetes, which eliminated the influence of diabetes on our results. Meanwhile, we did not find an association between PPAR- $\gamma 2$ Pro12Ala polymorphism and obesity and blood pressure, which also eliminated the influence of metabolic syndrome on our results. However, our subjects were selected from Han Chinese in Hohhot, not representative of the Chinese population, which was a limitation in our results. Therefore, further study with different ethnic groups, large samples and other genetic polymorphisms will better reveal the association between PPAR- $\gamma 2$ Pro12Ala polymorphism and MI and obesity.

\section{ACKNOWLEDGMENTS}

Research supported by the Inner Mongolia Natural Science Foundation Key Program (\#2010ZD26) and Science and Technology Bureau, Hohhot, Inner Mongolia (\#2006-Nong-Yi-2).

\section{REFERENCES}

Akiyama TE, Sakai S, Lambert G, Nicol CJ, et al. (2002). Conditional disruption of the peroxisome proliferator-activated receptor gamma gene in mice results in lowered expression of ABCA1, ABCG1, and apoE in macrophages and reduced cholesterol efflux. Mol. Cell Biol. 22: 2607-2619.

Altshuler D, Hirschhorn JN, Klannemark M, Lindgren CM, et al. (2000). The common PPARgamma Pro12Ala polymorphism is associated with decreased risk of type 2 diabetes. Nat. Genet. 26: 76-80.

Beamer BA, Yen CJ, Andersen RE, Muller D, et al. (1998). Association of the Pro12Ala variant in the peroxisome proliferator-activated receptor-gamma2 gene with obesity in two Caucasian populations. Diabetes 47: 1806-1808.

Black MH, Fingerlin TE, Allayee H, Zhang W, et al. (2008). Evidence of interaction between PPARG2 and HNF4A contributing to variation in insulin sensitivity in Mexican Americans. Diabetes 57: 1048-1056.

Genetics and Molecular Research 11 (3): 2929-2938 (2012) 
Bouhlel MA, Derudas B, Rigamonti E, Dievart R, et al. (2007). PPARgamma activation primes human monocytes into alternative M2 macrophages with anti-inflammatory properties. Cell Metab. 6: 137-143.

Danawati CW, Nagata M, Moriyama H, Hara K, et al. (2005). A possible association of Pro12Ala polymorphism in peroxisome proliferator-activated receptor gamma2 gene with obesity in native Javanese in Indonesia. Diabetes Metab. Res. Rev. 21: 465-469.

Deeb SS, Fajas L, Nemoto M, Pihlajamaki J, et al. (1998). A Pro12Ala substitution in PPARgamma2 associated with decreased receptor activity, lower body mass index and improved insulin sensitivity. Nat. Genet. 20: 284-287.

Ghoussaini M, Meyre D, Lobbens S, Charpentier G, et al. (2005). Implication of the Pro12Ala polymorphism of the PPAR-gamma 2 gene in type 2 diabetes and obesity in the French population. BMC Med. Genet. 6: 11.

Holvoet P (2008). Relations between metabolic syndrome, oxidative stress and inflammation and cardiovascular disease. Verh. K. Acad. Geneeskd. Belg. 70: 193-219.

Hsueh WA and Bruemmer D (2004). Peroxisome proliferator-activated receptor gamma: implications for cardiovascular disease. Hypertension 43: 297-305.

Hu Q, Zhang XJ, Liu CX, Wang XP, et al. (2010). PPARgamma1-induced caveolin-1 enhances cholesterol efflux and attenuates atherosclerosis in apolipoprotein E-deficient mice. J. Vasc. Res. 47: 69-79.

Issemann I and Green S (1990). Activation of a member of the steroid hormone receptor superfamily by peroxisome proliferators. Nature 347: 645-650.

Iwai M, Kanno H, Senba I, Nakaoka H, et al. (2011). Irbesartan increased PPARgamma activity in vivo in white adipose tissue of atherosclerotic mice and improved adipose tissue dysfunction. Biochem. Biophys. Res. Commun. 406: 123-126.

Ji Y, Liu J, Wang Z, Liu N, et al. (2009). PPARgamma agonist, rosiglitazone, regulates angiotensin II-induced vascular inflammation through the TLR4-dependent signaling pathway. Lab. Invest. 89: 887-902.

Kagawa Y, Yanagisawa Y, Hasegawa K, Suzuki H, et al. (2002). Single nucleotide polymorphisms of thrifty genes for energy metabolism: evolutionary origins and prospects for intervention to prevent obesity-related diseases. Biochem. Biophys. Res. Commun. 295: 207-222.

Kim KS, Choi SM, Shin SU, Yang HS, et al. (2004). Effects of peroxisome proliferator-activated receptor-gamma 2 Pro12Ala polymorphism on body fat distribution in female Korean subjects. Metabolism 53: 1538-1543.

Kolehmainen M, Uusitupa MI, Alhava E, Laakso M, et al. (2003). Effect of the Pro12Ala polymorphism in the peroxisome proliferator-activated receptor (PPAR) gamma2 gene on the expression of PPARgamma target genes in adipose tissue of massively obese subjects. J. Clin. Endocrinol. Metab. 88: 1717-1722.

Liu L, Liu L, Ding Y, Huang Z, et al. (2001). Ethnic and environmental differences in various markers of dietary intake and blood pressure among Chinese Han and three other minority peoples of China: results from the WHO Cardiovascular Diseases and Alimentary Comparison (CARDIAC) Study. Hypertens. Res. 24: 315-322.

Masud S and Ye S (2003). Effect of the peroxisome proliferator activated receptor-gamma gene Pro12Ala variant on body mass index: a meta-analysis. J. Med. Genet. 40: 773-780.

McDermott MM (2007). The international pandemic of chronic cardiovascular disease. JAMA 297: 1253-1255.

Meirhaeghe A, Fajas L, Helbecque N, Cottel D, et al. (2000). Impact of the peroxisome proliferator activated receptor gamma2 Pro12Ala polymorphism on adiposity, lipids and non-insulin-dependent diabetes mellitus. Int. J. Obes. Relat. Metab. Disord. 24: 195-199.

Miyazaki Y, Mahankali A, Matsuda M, Glass L, et al. (2001). Improved glycemic control and enhanced insulin sensitivity in type 2 diabetic subjects treated with pioglitazone. Diabetes Care 24: 710-719.

Moran CS, Cullen B, Campbell JH and Golledge J (2009). Interaction between angiotensin II, osteoprotegerin, and peroxisome proliferator-activated receptor-gamma in abdominal aortic aneurysm. J. Vasc. Res. 46: 209-217.

Mori H, Ikegami H, Kawaguchi Y, Seino S, et al. (2001). The Pro12 $\rightarrow$ Ala substitution in PPAR-gamma is associated with resistance to development of diabetes in the general population: possible involvement in impairment of insulin secretion in individuals with type 2 diabetes. Diabetes 50: 891-894.

Mori Y, Kim-Motoyama H, Katakura T, Yasuda K, et al. (1998). Effect of the Pro12Ala variant of the human peroxisome proliferator-activated receptor gamma 2 gene on adiposity, fat distribution, and insulin sensitivity in Japanese men. Biochem. Biophys. Res. Commun. 251: 195-198.

Pan XF, Song XB, Wang LL, Li LX, et al. (2009). Association of the Pro12Ala polymorphism in peroxisome proliferators activated receptor-gamma gene with rheumatoid arthritis in Sichuan Province of China. Zhonghua Yi Xue Yi Chuan Xue Za Zhi 26: 87-90.

Ren Y, Sun C, Sun Y, Tan H, et al. (2009). PPAR gamma protects cardiomyocytes against oxidative stress and apoptosis via Bcl-2 upregulation. Vascul. Pharmacol. 51: 169-174.

Ridker PM, Cook NR, Cheng S, Erlich HA, et al. (2003). Alanine for proline substitution in the peroxisome proliferatoractivated receptor gamma-2 (PPARG2) gene and the risk of incident myocardial infarction. Arterioscler. Thromb. Vasc. Biol. 23: 859-863. 
Rose GA and Blackburn H (1982). Cardiovascular Survey Methods. World Health Organization. WHO Monograph Series, Geneva.

Schaffler A, Barth N, Schmitz G, Zietz B, et al. (2001). Frequency and significance of Pro12Ala and Pro115Gln polymorphism in gene for peroxisome proliferation-activated receptor-gamma regarding metabolic parameters in a Caucasian cohort. Endocrine. 14: 369-373.

Stefanski A, Majkowska L, Ciechanowicz A, Frankow M, et al. (2006). Lack of association between the Pro12Ala polymorphism in PPAR-gamma2 gene and body weight changes, insulin resistance and chronic diabetic complications in obese patients with type 2 diabetes. Arch. Med. Res. 37: 736-743.

Tamori Y, Masugi J, Nishino N and Kasuga M (2002). Role of peroxisome proliferator-activated receptor-gamma in maintenance of the characteristics of mature 3T3-L1 adipocytes. Diabetes 51: 2045-2055.

Tavares V, Hirata RD, Rodrigues AC, Monte O, et al. (2005). Association between Pro12Ala polymorphism of the PPARgamma2 gene and insulin sensitivity in Brazilian patients with type-2 diabetes mellitus. Diabetes Obes. Metab. 7: 605-611.

Wang G, Wei J, Guan Y, Jin N, et al. (2005). Peroxisome proliferator-activated receptor-gamma agonist rosiglitazone reduces clinical inflammatory responses in type 2 diabetes with coronary artery disease after coronary angioplasty. Metabolism 54: 590-597.

Wei Q, Jacobs DR, Jr., Schreiner PJ, Siscovick DS, et al. (2006). Patterns of association between PPARgamma genetic variation and indices of adiposity and insulin action in African-Americans and whites: the CARDIA Study. J. Mol. Med. 84: 955-965.

Yamamoto Y, Hirose H, Miyashita K, Nishikai K, et al. (2002). PPAR(gamma)2 gene Pro12Ala polymorphism may influence serum level of an adipocyte-derived protein, adiponectin, in the Japanese population. Metabolism 51: 14071409.

Yen CJ, Beamer BA, Negri C, Silver K, et al. (1997). Molecular scanning of the human peroxisome proliferator activated receptor gamma (hPPAR gamma) gene in diabetic Caucasians: identification of a Pro12Ala PPAR gamma 2 missense mutation. Biochem. Biophys. Res. Commun. 241: 270-274.

Zafarmand MH, van der Schouw YT, Grobbee DE, de Leeuw PW, et al. (2008). Peroxisome proliferator-activated receptor gamma-2 P12A polymorphism and risk of acute myocardial infarction, coronary heart disease and ischemic stroke: a case-cohort study and meta-analyses. Vasc. Health Risk Manag. 4: 427-436. 